\title{
Turning Our Faces Toward the New...
}

\author{
Arthur M. Michalek
}

Published online: 24 January 2015

(C) Springer Science+Business Media New York 2015

Happy New Year! With this issue, we begin a new year and pause to give thanks for past achievements and thought to new endeavors. It has been a remarkable year. In many ways, the Journal's year has been much like the year we have all personally experienced. This has been a year that has brought achievements and some challenges. A year where we said goodbye to some of our organization's pioneers and hello to new members who will become tomorrow's leaders. These sensitivities are particularly acute having recently attended the International Cancer Education Conference (i.e., annual AACE/CPEN meeting). That meeting marks the end of one year and the beginning of another in the life of our organizations and was certainly true to the tradition of past years. Old acquaintances gathered together; new acquaintances made; lessons shared; and future plans devised. At the annual editorial board meeting, we reviewed the past years achievements and discussed future initiatives.

Particularly noteworthy was the announcement at the board meeting that the impact factor for the journal has broken one. We are now at 1.05. While this does not move the journal into the highest impact arena, it does represent significant progress. A year ago, we were at .88, and 7 years ago, it stood at .34. The journal has made significant strides over a short span of time. A journal's impact factor, as a refresher, is the average number of citations received per paper published in that journal. Thus, the journal's impact factor will increase the more frequently articles published in the Journal of Cancer Education (JCE) are referenced in other papers. A rising impact factor is thought to represent

A. M. Michalek ( $\triangle)$

Division of Health Services Policy and Practice,

School of Public Health and Health Professions,

University at Buffalo, Buffalo, NY, USA

e-mail: jceditor1@gmail.com increasing quality. The perceived quality of the JCE has risen steadily over the past several years. This is due to the quality of the papers we publish and for that we must think all of our authors for submitting such superb work. I would also like to thank our reviewers who spend countless hours critiquing and submitting recommendations leading to ever stronger papers. Authors and reviewers are not, as some might believe, adversarial, but are quasi-partners in advancing and enhancing our scientific work. The perceived increased quality of the journal has resulted in ever-increasing numbers of submissions and, consequently, increased selectivity. Over the past 3 years, submissions have risen by $55 \%$ affording an increase in selectivity by $43 \%$. The journal is also becoming recognized as the international home for papers on training and education. The number of manuscripts published by groups from outside North America has grown quite dramatically with the proportion of published manuscripts from outside North America growing to over one quarter of total articles. The JCE is truly an international journal with plans to further develop this niche. We are also becoming more efficient in transmitting decisions back to authors. In 2010, the average time from submission to first decision was 74 days; in 2013, it was 34 days; and through the first three quarters of 2014, it was 22 days. Again, thanks go to our dedicated reviewers. Another notable indicator of the recognized quality of manuscripts published in the journal is the number of articles downloaded. The number of downloads via SpringerLink has grown over 3 years from 19,000 downloads to nearly 42,000 downloads. Special kudos to those authors whose articles were most in demand. Three manuscripts published in 2013 that have led the way in downloads were authored by Julie Mason [1], Julie Kapp [2], and Ambarish Pandey [3]. Congratulations!

The above details were shared at our editorial board meeting held in conjunction with the International Cancer 
Education Conference held this past October in Clearwater Beach, Florida. The meeting was a resounding success that once again brought together members of the AACE, CPEN, and EACE. Attendees enjoyed a marvelous venue and had an ample opportunity to network and, most importantly, to enjoy excellent podium and poster presentations. There were also a number of excellent preconference workshops and plenary sessions. The keynote plenary session was given by Dr. Amr Soliman, President-Elect of the AACE, on challenges and opportunities of cancer education in low- and middle-income countries. Dr. Solomon is Chair of Epidemiology at the University of Nebraska where he also directs an international program and is thus well-positioned to address this topic. Attendees were provided with a realistic view of cancer patterns in these countries and opportunities for making significant contributions to the health of these peoples. The annual Samuel C Harvey Memorial lecture was given by Dr. Cathy Meade from the Moffitt Cancer Center. Dr. Mead is a long-term member of AACE and CPEN and, most relevant to this award, a pioneer in the field of culture and literacy in cancer education. Her insights into the nuances of culture and language and how it affects message reception was extremely poignant and will have an incredible influence on all of us who work in multicultural populations. We were then treated to a presentation on the role of philanthropy and cancer education given by Amy Deshler of the Mayo Clinic. Saturday's program was highlighted by a presentation given by Dr. Dark and Professor Starmer from the EACE on assessment and cancer education. Another outstanding presentation was given by two talented individuals who always are willing to share their knowledge at our annual meetings. I only hope that they will continue this tradition next year as we gather in Tucson Arizona on October 21-24. Please put this date down in your calendar and check for details at www.attendicec.org/ or www. aaceonline.com/.

It is impossible for me to highlight all the stellar presentations proffered at this meeting, but hope that all who contributed will transform their presentations into JCE publications so that all our readers may benefit. A number of awards were presented in a variety of categories. Chief among these was the Margaret Hay Edwards Achievement Award, the highest recognition given by the AACE, and this year presented to Dr. Pamela Catton. Dr. Catton was also fighting her only battle with cancer. Unfortunately, that ended on December 23, 2014. Her contributions and effect on others will be related by Dr. Wiljer in a separate piece. Her passing is even more evidence of the toll cancer takes of the individual, family, and society. Dr. Catton was a radiation oncologist who specialized in breast cancer as well as a teacher and education researcher. She was the Director of Cancer Education at the University Health Network, as well as the Medical Director of Cancer Survivorship and Patient Education at the Princess Margaret Cancer Centre, Toronto, Ontario, Canada. Dr. Catton was widely known as an innovator in education and had made significant contributions to the field of cancer education for patients, students, physicians-in-training, and health care practitioners. A well-deserved and timely honor!

Best Poster Awards were made to Carolyn Messner, Meg McCallum, and a group led by Yonaira M. Rivera. Best abstract awards were presented to Stephanie Kennedy et al., Ivan Valverde et al., and Pedram Daraei. Due to space limitations, I am unable to fully site their work or explain their contributions. I suggest that you visit http://aaceonline.com/ AwardsHonors.html for a full accounting of this year's awards.

I recently read a wonderful book by Hampton Sides entitled "In the Kingdom of the Ice" [4]. This book details the remarkable story of a group of adventurers who set out in 1879 to travel to the North Pole via water route. This tale is told in such vivid detail that even those of us who live in Buffalo cringe at the thought of being entrapped in ice... again. There is one particular speech given by the leader of this group (De Long) on the occasion of New Year's Eve. This speech is worthy of comment given its sentiment and parallel to our adventures in cancer education. In it he states:

this cruise may be divided into two parts: that which has been and that which is to be. We are about to turn our backs on the old year and turn our faces toward the new. During the past 16 months we have drifted 1300 miles. Danger has confronted us each day. We have been squeezed and jammed, tossed and tumbled, nipped and pressed, until the ship hull would have burst had it not been as strong as the hearts it held within. We have pumped a leaking ship for a year and kept her habitable. And we are all still here. We face the future with the firm hope of doing something worthy of ourselves, and worthy of the flag that floats above us. We are not yet daunted.

Let us take these words to heart as we look back on the past year and know that while the field of cancer education and training has seen some successes, we have also seen some challenges and failures. Yet, throughout it all, we gather together each year and through the pages of this journal to revel in our successes and to share challenges for the future. May we, just as the crew of the Jeanette, remain undaunted.

Happy New Year and Be Well.

Arthur M. Michalek, PhD, FACE 


\section{References}

1. Mason JL, Lei M, Faupel-Badger JM, Ginsburg EP, Seger YR, DiJoseph L, Schnell JD, Wiest JS (2013) Outcome evaluation of the National Cancer Institute Career Development Awards Program. J Cancer Educ 28(1):9-17
2. Kapp JM, Peters C, Parker Oliver D (2013) Research recruitment using Facebook advertising: big potential, big challenges. J Cancer Educ 28(1):134-137

3. Pandey A, Hasan S, Dubey D (2013) Smartphone Apps as a source of cancer information: changing trends in health information-seeking behavior. J Cancer Educ 28(1):138-142

4. Hampton S (2014) In the Kingdom of Ice. Doubleday Random House 